\title{
Normative decomposition of the profit bridge into the impact of changes in marketing variables
}

\author{
Tim J. Smith ${ }^{1}$
}

Received: 22 September 2020 / Accepted: 9 November 2020 / Published online: 4 January 2021

(c) The Author(s) 2021

\begin{abstract}
A set of definitions and equations for measuring the impact of changes in quantity sold, price, variable costs, and mix between two time periods on the business's profitability are provided. The recommended decomposition of the changes in profit is then compared with four other seemingly rational decompositions using hypothetical two-product firms. The comparisons demonstrate the importance of using a proper decomposition in constructing a measurement of the impacts of changes in quantity sold, price, variable costs, and mix on the profitability over other formulations and prior art. This normative decomposition of the profit bridge measuring the impact of changes in marketing activities is used as part of the intelligence mosaic in executive and investor decision-making.
\end{abstract}

Keywords Profit bridge $\cdot$ Margin analysis $\cdot$ Analytic modeling $\cdot$ Attribution $\cdot$ Measurement

\section{Introduction}

When comparing the profit performance of a company between periods, decision makers often seek to attribute the origin of changes in profits to changes in various business variables. With respect to marketing decisions and outcomes, they specifically seek to decompose the changes in profits connecting one period to another in measurements of the impacts in changes of quantity sold, prices, variable costs, offering mix, new offerings, and retired offerings. In doing so, they are seeking to measure the performance of specific business variables under management in comparison to a prior period.

An appropriately defined profit bridge will connect the profits of one period to another with clear measurements of the impact of changes in business variables between those time periods. It will provide understandable and recognizable facts for ease of communication and decision-making. While alone, a profit bridge cannot definitively state what actions to take, combined with other measurements and business intelligence, it can lead to better decision-making. Moreover, it apparently has interest to investors as some

Tim J. Smith

tsmith@wiglafpricing.com

1 Wiglaf LLC, 2607 W. Augusta Blvd, Chicago, IL 60622, USA companies communicate their profit bridge to investors in quarterly and annual reports.

Executives may use the profit bridge to evaluate the company overall, a division of the company, a customer segment, or a single customer. The period of analysis could be a year, quarter, month, week, or day compared to an equal period in the past. This will lead to studies of this year compared to last year, this quarter compared to last quarter, or this quarter compared to the same quarter last year of the company, a line of business within the company, a customer segment, or even a single customer.

Similar equations can be produced to make a similar revenue bridge by simply removing the variable costs and other appropriate adjustments. Similarly, margin bridges can be constructed. Other profit bridges disaggregate specific changes in the cost structure. Profit bridges can also be written to isolate the impact of changes in exchange rates. Here, the focus is on a profit bridge that decomposes changes in profits to common marketing variables and ignores other issues, such as exchange rates and fixed cost changes, for the sake of simplicity. These other effects may easily be included as needed, yet it is not the purpose of this paper to describe an exhaustive list of sound profit bridges. Rather, this paper seeks to elucidate a normative practice for a simple profit bridge that measures the impacts of changes in quantity sold, prices, variable costs, mix, and product entrances and exits. 
In this article, the basic equations for a generalized profit bridge with proper attribution recommended for use by any company are provided. Implementation of these equations can be done via spreadsheet analysis, various programing languages, or specialized software.

Although the decomposition of profits between any two periods can be done in an infinite number of manners, not all decompositions lead to clear, meaningful measurements. For a profit bridge to be useful, it must meet at least four criteria: First, the sum of the measurements must add to the actual change of profits. Second, the individual measurements should be clear and discernable as it relates to actual changes in underlying marketing variables. Third, the measurements should provide sufficient specificity so as to enable the evaluation of the outcomes of specific strategies. And fourth, the measurements should be symmetric as it relates to the direction of time's arrow, meaning that the measurements going forward in time should produce equal and opposite measurements when going backwards in time.

Beyond the profit bridge with proper attribution, we examine four alternative profit bridges which have seemingly appropriate definitions, yet are found to fall short of leading to clear meaningful measurements. All the profit bridges described meet the first, basic criteria. They do not necessarily meet all four criteria. The alternative profit bridges are the profit bridge with unattributed impacts, a profit bridge subsuming mix changes in the quantity sold term, a profit bridge subsuming mix changes in the price and variable cost term, and an inelegant profit bridge with misattribution.

We demonstrate the shortcomings of the alternative profit bridges in comparison to that with proper attribution by examining their implementation on hypothetical two-product firms and comparing the results against that which one would have intuitively expected. In doing so, we highlight the importance of having a well-defined profit bridge with clear attribution to enable the measurement of the success or failure of a given strategy and the attribution of the success or failure to the specific marketing variables either directly managed by decisions or impacted by the outcome of those decisions.

\section{Related literature}

The only published profit bridge with equations was found in a patent. Unfortunately, the equations contained in that patent will be shown to lead to a misattribution of the impacts across multiple business variables in comparison to that with proper attribution (Early 2013).

Profit bridges which seek to decompose the profit impacts of changes in quantity sold, price, variable costs, and mix are marketed under various names as part of several pricing
Table 1 Notation for business variables of product $\mathrm{j}$ in time period 1 or 2

\begin{tabular}{lll}
\hline & Period 1 & Period 2 \\
\hline Quantity sold & $Q_{j 1}$ & $Q_{j 2}$ \\
Price & $P_{j 1}$ & $P_{j 2}$ \\
Variable cost & $V_{j 1}$ & $V_{j 2}$ \\
\hline
\end{tabular}

software solutions. (Vendavo n.d.; Kini Group n.d.; Zurek 2013). However, as proprietary solutions, the specific equations behind the profit bridges implemented by specific software vendors is unpublished. As such, we are uncertain of how these profit bridges are defined or if they are meaningful.

Similarly, multiple companies decompose the profit impacts of marketing variables in corporate investor reports. Sometimes, the profit impacts of changes in marketing variables have lack of a clear definition (Gurit 2014). Sometimes, they decompose the profit impacts of changes in quantity sold, weighted average price, and weighted average variable costs where the impacts of mix are subsumed within the attributed impacts of the weighted average price and variable costs. (Noranda Aluminium Holding Corp 2011; Pirelli 2016; Matchett 2016; Lumber Liquidators 2015) Sometimes, the impacts of changes in foreign exchange are also specifically identified (Szramiak 2016). Yet, once again, the specific equations behind these profit bridges are unpublished.

While proprietary methods are common, the resulting analysis from the proprietary methods can be of dubious quality as it lacks peer review and clarity in definition.

The purpose of this publication is to both (1) elucidate the seemingly rational approaches one can make to lead to an algebraically correct profit bridge and (2) clarify how a specific approach to constructing the profit bridge is both algebraically correct and delivers clear measurements while others can be misleading or incomplete even though algebraically true.

\section{Profit bridges}

For specific product $\mathrm{j}$ within a specific time period, denote the quantity sold as $\mathrm{Q}_{\mathrm{j}}$, the average price as $P_{\mathrm{j}}$, and the average variable cost as $V_{j}$. Furthermore, identify the period under consideration with the subscript 1 or 2 for first and second period, respectively (see Table 1).

The change in profits, $\Delta R$, is defined as the profits earned in period 2 less the profits earned in period 1 using the standard profit equation of the firm and ignoring fixed cost. 
$\Delta R=\sum_{j \in \text { all }}\left[Q_{j 2}\left(P_{j 2}-V_{j 2}\right)-Q_{j 1}\left(P_{j 1}-V_{j 1}\right)\right]$

Profit bridges seek to decompose the change in profit to discrete terms. For marketing purposes, these terms are designed to show the impact of changes in quantity sold, prices, variable costs, new product entrances, old product exits, and other factors. Thus, profit bridges can be generalized as

$\Delta R=\mathrm{QX}+\mathrm{PX}+\mathrm{VX}+\mathrm{ENT}+\mathrm{EXT}+\mathrm{OTHER}$

where the measured impact on profits of various changes in marketing variables is attributed to QX for quantity sold, PX for prices, VX for variable costs, ENT for new product entrances, and EXT for product exits. OTHER can be a number of terms that attribute the change in profits to other business variables. We recommend that OTHER should minimally include a mix term for any company with more than one product for managerial decision-making though this term may be unnecessary for investor communications.

The demarcation of $\mathrm{X}$ in profit bridge denotes that the decomposition of profits into discrete terms can be done in infinite manners. Unfortunately, these variations in profit decomposition will lead to different measurements of the impacts of changes in marketing variables on profits. While competing decompositions may be algebraically accurate, most will lead to uncertain, confusing, or inaccurate measurements of the impacts of changes in business variables on the change in profits and therefore be useless for guiding decision-making or evaluating the outcome of past decisions.

\section{Profit bridge with proper attribution}

The Profit Bridge with Proper Attribution will define clear measurements of the impacts of changes in quantity sold, price, variable costs, product entrances, product exits, and product mix. We will demark this profit bridge with the letter I for Impact. See Eq. 3.

$\Delta R=Q I+P I+V I+M I+E N T+E X T$

The six terms in the profit bridge are carefully defined to deliver clear, meaningful, and accurate measurements. Their definition is provided after introducing simplifying terms.

\section{Definitions}

Denote the mix contribution for calculating the quantity weighted averages of a term as $\mathrm{M}_{\mathrm{j} 1}$ and $\mathrm{M}_{\mathrm{j} 2}$ in time periods 1 and 2.
$M_{j 1}=\frac{Q_{j 1}}{\sum_{j} Q_{j 1}}$

$M_{j 2}=\frac{Q_{j 2}}{\sum_{j} Q_{j 2}}$

For specific product $\mathrm{j}$, the average across the two periods of quantity sold is calculated $\overline{\mathrm{Q}_{j}}$, of price $\overline{P_{\mathrm{j}}}$, of variable cost $\bar{V}_{\mathrm{j}}$, and mix contribution $\bar{M}_{j}$ using the standard concept of arithmetic mean.

$\overline{Q_{j}}=\left(Q_{j 2}+Q_{j 1}\right) / 2$

$\overline{P_{j}}=\left(P_{j 2}+P_{j 1}\right) / 2$

$\overline{V_{j}}=\left(V_{j 2}+V_{j 1}\right) / 2$

$\overline{M_{j}}=\left(M_{j 2}+M_{j 1}\right) / 2$

Similarly, for specific product $\mathrm{j}$, calculate the change between the two periods in quantity sold $\Delta Q_{j}$, in price $\Delta P_{j}$, in variable cost $\Delta V_{j}$, and mix contribution $\Delta M_{j}$ using the standard concept of differences.

$\Delta Q_{j}=Q_{j 2}-Q_{j 1}$

$\Delta P_{j}=P_{j 2}-P_{j 1}$

$\Delta V_{j}=V_{j 2}-V_{j 1}$

$\Delta M_{j}=M_{j 2}-M_{j 1}$

For the overall business under analysis, calculate the averages across the two periods in quantity sold $\bar{Q}$, inter-period weighted average price $\bar{P}$, and inter-period weighted average variable cost $\bar{V}$. Importantly, while Eq. 6 can be used for calculating the average quantity sold, Eqs. 7-8 are not used for calculating the overall business's average price and variable cost across the two periods. (Equations 7-9 will be used later.)

$\bar{Q}=\sum_{j \epsilon \mathrm{CONT}} \overline{Q_{j}}$

$\bar{P}=\sum_{j \in \mathrm{CONT}}\left(M_{j 2} P_{j 2}+M_{j 1} P_{j 1}\right) / 2$

$\bar{V}=\sum_{j \epsilon \mathrm{CONT}}\left(M_{j 2} V_{j 2}+M_{j 1} V_{j 1}\right) / 2$ 
These averages are calculated for continuing products appearing in both time periods only. ( $j \epsilon$ CONT denotes we are only including continuing products in the sum). The analysis of the impacts of product exits and entrances will be conducted separately.

Similarly, for the overall business under analysis, calculate between the two periods the total change in quantity sold $\Delta Q$, the weighted average change in prices $\Delta P$, and the weighted average change in variable cost $\Delta V$. Importantly, the changes in weighted average price and variable cost use the average mix contribution across both periods of time of product j. Equations 17-19 have used Eqs. 10-12 and Eq. 9.

$\Delta Q=\sum_{j \in \mathrm{CONT}} \Delta Q_{j}$

$\Delta P=\sum_{j \in \mathrm{CONT}} \Delta P_{j} \bar{M}_{j}$

$\Delta V=\sum_{j \in \mathrm{CONT}} \Delta V_{j} \overline{M_{j}}$

With these definitions, we can write QI, PI, VI, MI, ENT, and EXT as follows. QI measures the impact of changes in quantity sold on profits. It is the total change in quantity sold times the difference of the inter-period weighted average price and variable cost. Using Eqs. 17 and 15-16, QI can be written as follows:

$$
\begin{aligned}
Q I= & \Delta Q(\bar{P}-\bar{V})=\left(\sum_{j \epsilon \mathrm{CONT}} Q_{j 2}-Q_{j 1}\right) \\
& \left(\sum_{j \epsilon \mathrm{CONT}} \frac{M_{j 2}\left(P_{j 2}-V_{j 2}\right)+M_{j 1}\left(P_{j 1}-V_{j 1}\right)}{2}\right)
\end{aligned}
$$

PI measures the impact of changes in specific prices on profits. It is the average quantity sold times the weighted average change in prices where the weighting uses the average quantity weighting across the two periods. Using Eqs. 18 and 14 , PI can be written as

$P I=\bar{Q} \Delta P=\left(\sum_{j \epsilon \mathrm{CONT}} \frac{Q_{j 2}+Q_{j 1}}{2}\right)\left(\sum_{j \epsilon \mathrm{CONT}} \frac{M_{j 2}+M_{j 1}}{2}\left(P_{j 2}-P_{j 1}\right)\right)$

VI measures the impact of changes in specific variable costs on profits. It is the average quantity sold times weighted average change in variable costs where the weighting uses the average quantity weighting across the two periods. Using Eqs. 19 and 14, QI can be written as follows:

$V I=-\bar{Q} \Delta V=-\left(\sum_{j \epsilon \mathrm{CONT}} \frac{Q_{j 2}+Q_{j 1}}{2}\right)\left(\sum_{j \epsilon \mathrm{CONT}} \frac{M_{j 2}+M_{j 1}}{2}\left(V_{j 2}-V_{j 1}\right)\right)$
MI measures the impact of changes in the product mix on profits. It is the product of the average quantity sold and the sum of the differences in individual products of their average price and variable cost across the two periods times their change in mix contribution between the two periods. Using Eqs. 14, 7-8, and 13, MI can be written as follows:

$$
\begin{aligned}
M I= & \bar{Q} \sum_{j}\left(\overline{P_{j}}-\bar{V}_{j}\right) \Delta M_{j}=\left(\sum_{j \epsilon \mathrm{CONT}} \frac{Q_{j 2}+Q_{j 1}}{2}\right) \\
& \left(\sum_{j \epsilon \mathrm{CONT}}\left(M_{j 2}-M_{j 1}\right) \frac{\left(P_{j 2}+P_{j 1}\right)-\left(V_{j 2}+V_{j 1}\right)}{2}\right)
\end{aligned}
$$

ENT measures the impact of new product entrances on profits. It is the quantity sold times the difference in price and variable cost of new products introduced during the second period. ( $j \epsilon$ ENT denotes we are only including new products in the sum.)

$\mathrm{ENT}=\sum_{j \in \mathrm{ENT}} Q_{j 2}\left(P_{j 2}-V_{j 2}\right)$

EXT measures the impact of old product exits on profits. It is the quantity sold times the difference in price and variable cost of exiting products removed from the second period, but appearing in the first. ( $j \epsilon$ EXT denotes we are only including exiting products in the sum.)

$\mathrm{EXT}=-\sum_{j \in \mathrm{EXT}} Q_{j 1}\left(P_{j 1}-V_{j 1}\right)$

\section{Application}

Appling the Profit Bridge with Proper Attribution to a simple hypothetical two-product firm demonstrates its clarity and accuracy of measurement for decision-making.

Five hypothetical two-product firms are constructed to show the clarity of measurements made by the Profit Bridge with Proper Attribution over those made with alternative profit bridges. Each of the hypothetical firms are posited to have undertaken a different strategy to improve profits. After the strategy had been implemented, the results of their strategy are measured and attributed to changes in specific marketing variables. We make the simplifying assumption of no product entrances or exits as these terms are relatively trivial to calculate.

Comparison of the Profit Bridge with Proper Attribution to alternative profit bridges will be made after defining the alternatives. Importantly, the alternative profit bridges must, at a minimum, make similarly clear and proper measurements as that of the Profit Bridge with Proper Attribution. 
Table 2 Hypothetical two-product firm growth

\begin{tabular}{lccccr}
\hline Product & \multicolumn{2}{l}{ Period 1 } & & Period 2 & \\
\cline { 2 - 3 } \cline { 5 - 6 } & $\mathrm{A}$ & $\mathrm{B}$ & & $\mathrm{A}$ & $\mathrm{B}$ \\
\hline Quantity sold & 25 & 50 & & 38 & 76 \\
Price & 20 & 10 & 20 & 10 \\
Variable cost & 3 & 6 & 3 & 6 \\
Total profit & $\mathrm{R} 1=625$ & & $\mathrm{R} 2=950$ & \\
\hline
\end{tabular}

Table 3 Profit Bridge with proper attributions for firm growth

\begin{tabular}{llr}
\hline Measurement & Term & Value \\
\hline Impact of changes in quantity sold & QI & 325 \\
Impact of changes in prices & PI & 0 \\
Impact of changes in variable costs & VI & 0 \\
Impact of changes in product mix & MI & 0 \\
Impact of product entrances & ENT & 0 \\
Impact of product exits & EXT & 0 \\
Impact of product exits & $\Delta R$ & 325 \\
\hline
\end{tabular}

In Table 2, we provide the business variables across the two periods for a firm which strategically determined to grow the quantity sold with no changes in prices or variable costs. This is a trivial scenario that all profit bridges should be able to clearly demonstrate the impact of growth. This may be the result of a strategy that relied upon pressuring salespeople to sell more, adding to the sales force and/or distribution channel(s), or a company in a high-growth industry. Name this Firm Growth.

In period one, the total quantity sold across two products is 75 units. In period two, after the strategy was successfully implemented and executed, the total quantity sold was measured to have risen $52 \%$ to 114 units. Other marketing variables remained unchanged with prices of 20 and 10 for products A and B, respectively, and variable costs of 3 and 6 for products $\mathrm{A}$ and $\mathrm{B}$, respectively. As a result, profits (denoted by $\mathrm{R}$ for rents) rose by 325 from 625 to 950 .

For Firm Growth in Table 2, Profit Bridge with Proper Attribution would appropriately yield measurements that show there were no impacts outside of that arising from a change in quantity of products sold. See Table 3 and Fig. 1.

Notice that all changes in profits are attributed to a change in the quantity sold. This is in congruence with the measured outcome of the strategy of Firm Growth and is managerially meaningful as other marketing variables across the two time periods remained the same. In this scenario, the strategic decision to grow sales had an observable and measurable positive impact on profits.

In Table 4, we provide the business variables across the two periods for a firm in which it is strategically determined to increase prices on a select product with the hope of having no impact on the quantity sold. This too is a trivial scenario that all profit bridges should be able to clearly demonstrate the impact of changing prices. This may be the result of

Table 4 Hypothetical two-product firm price

\begin{tabular}{lccccr}
\hline Product & Period 1 & & & Period 2 & \\
\cline { 2 - 3 } \cline { 5 - 6 } & A & B & & A & B \\
\hline Quantity sold & 25 & 50 & 25 & 50 \\
Price & 20 & 10 & 33 & 10 \\
Variable cost & 3 & 6 & 3 & 6 \\
Total profit & R1 $=625$ & & & R2 $=950$ & \\
\hline
\end{tabular}

Fig. 1 Profit Bridge with proper attributions for firm growth

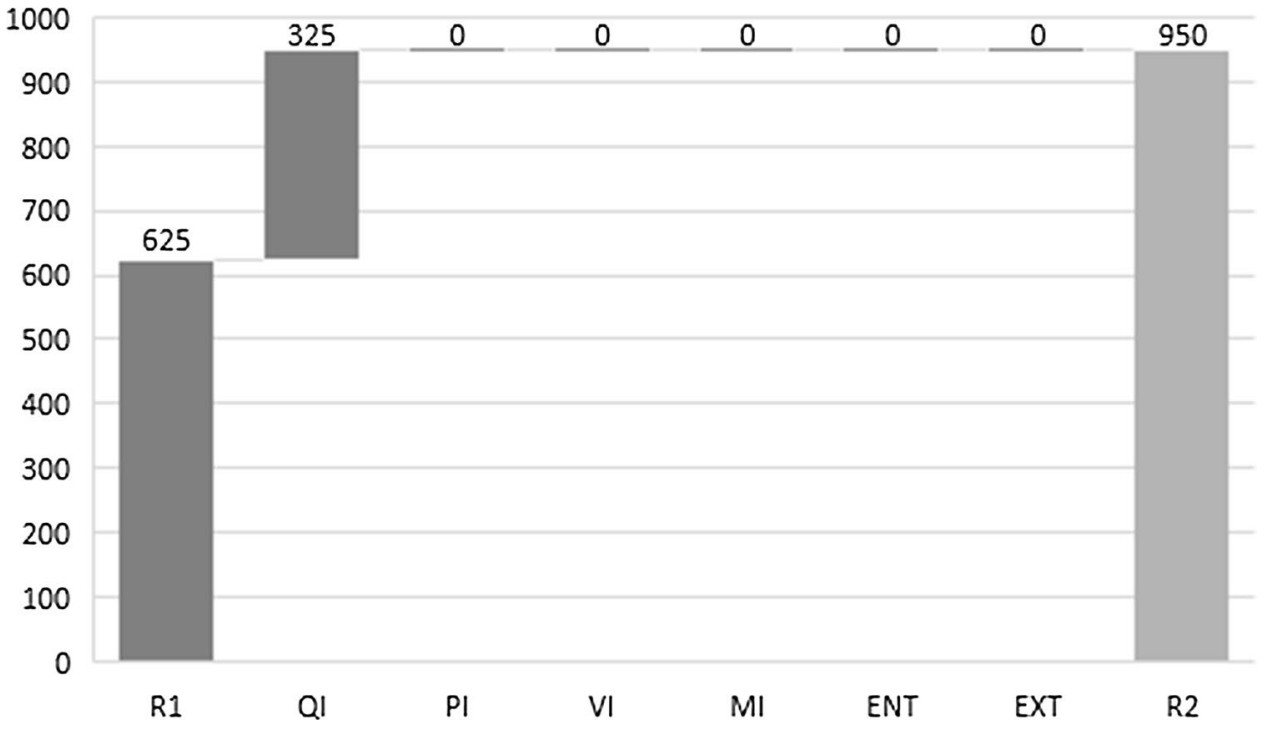


Table 5 Profit Bridge with proper attributions for firm price

\begin{tabular}{llr}
\hline Measurement & Term & Value \\
\hline Impact of changes in quantity sold & QI & 0 \\
Impact of changes in prices & PI & 325 \\
Impact of changes in variable costs & VI & 0 \\
Impact of changes in product mix & MI & 0 \\
Impact of product entrances & ENT & 0 \\
Impact of product exits & EXT & 0 \\
Impact of product exits & $\Delta R$ & 325 \\
\hline
\end{tabular}

a strategy to take advantage of inelasticity in the market, within specific accounts, or within specific products. Name this Firm Price.

In period one, the price on product A was 20 and B was 10. In period two, Firm Price selectively raised the price on product $\mathrm{A}$ to 33 while leaving the price on product $\mathrm{B}$ unchanged. Variable costs of 3 and 6 for products A and B, respectively, were unchanged between the two periods. In period one, the total quantity sold across two products is 75 units. In period two, after the strategy was successfully implemented and executed, the total quantity sold and mix of offerings sold was measured to have been unchanged. As a result, profits again rose 325 from 625 to 950 .

For Firm Price described in Table 4, the Profit Bridge with Proper Attribution would appropriately yield measurements that show there were no impacts outside of that arising from changes in price. See Table 5 and Figure 2.

In Table 6, we provide the business variables across the two periods for a firm in which strategically determined to improve the mix of offering sold with the hope of having no impact on the total quantity sold. This is a non-trivial scenario that requires accurately attributing the impact
Table 6 Hypothetical two-product firm mix

\begin{tabular}{lccccr}
\hline Product & Period 1 & & & Period 2 & \\
\cline { 2 - 3 } \cline { 6 - 6 } & A & & & A & B \\
\hline Quantity sold & 25 & 50 & & 50 & 25 \\
Price & 20 & 10 & 20 & 10 \\
Variable cost & 3 & 6 & 3 & 6 \\
Total profit & $\mathrm{R} 1=625$ & & & R2 $=950$ & \\
\hline
\end{tabular}

of changes in mix. This may be the result of a strategy to improve sales incentives, marketing communications, or driving customers to upgrade their offering selection. Name this Firm Mix.

In period one, Firm Mix sold 25 and 50 units of product $A$ and $B$, respectively, for a total of 75 units. In period two, after the strategy was successfully implemented and executed, the total quantity sold was measured to remain unchanged at 75 but the mix of offering had been successfully flipped to now 50 and 25 units of product A and $\mathrm{B}$, respectively. Other marketing variables remained unchanged with prices of 20 and 10 for products $A$ and $\mathrm{B}$, respectively, and variable costs of 3 and 6 for products $\mathrm{A}$ and $\mathrm{B}$, respectively. As a result, profits again rose 325 from 625 to 950 .

For Firm Mix described in Table 6, the Profit Bridge with Proper Attribution would appropriately yield measurements that show there were no impacts outside of that arising from changes in mix. See Table 7 and Figure 3.

In Table 8, we provide the business variables across the two periods for a firm in which strategically determined to improve one product and raise its price and degrade another product and lower its price with the hope of having no impact on the quantity sold. This is a highly non-trivial
Fig. 2 Profit bridge with proper attributions for firm price

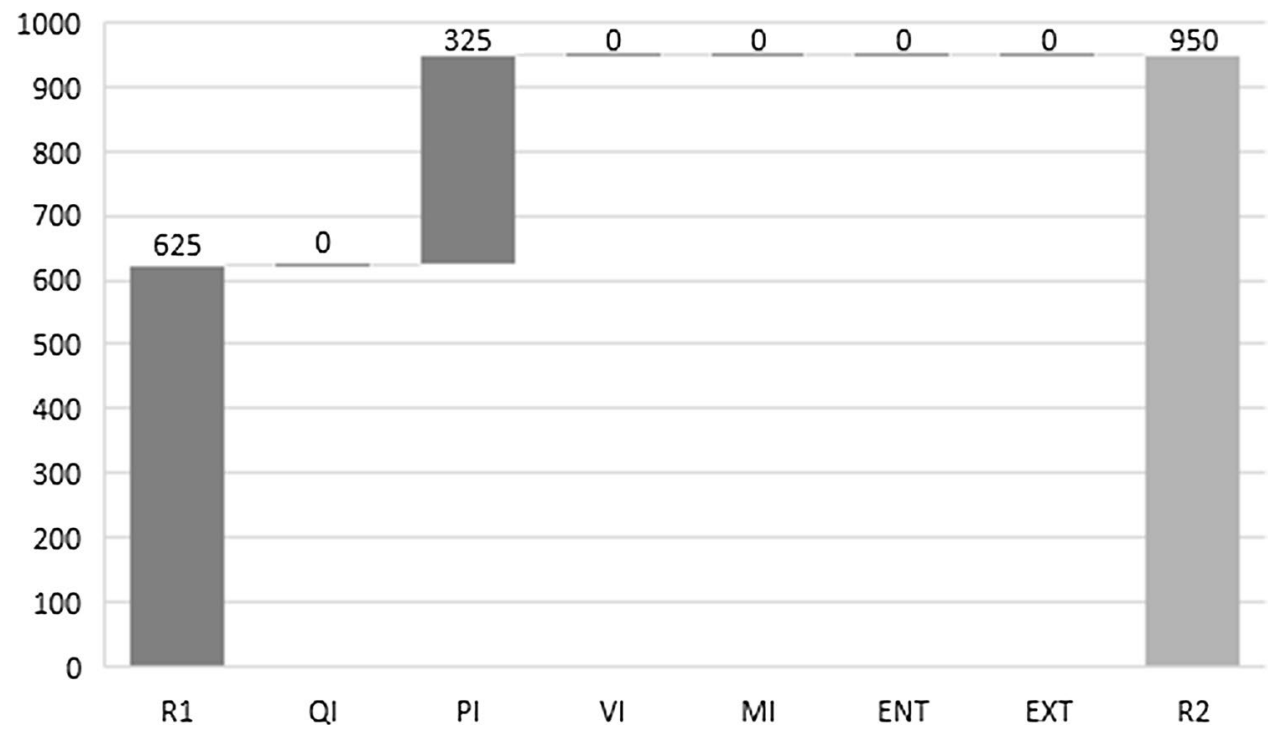


Table 7 Profit Bridge with proper attributions for firm mix

\begin{tabular}{llr}
\hline Measurement & Term & Value \\
\hline Impact of changes in quantity sold & QI & 0 \\
Impact of changes in prices & PI & 0 \\
Impact of changes in variable costs & VI & 0 \\
Impact of changes in product mix & MI & 325 \\
Impact of product entrances & ENT & 0 \\
Impact of product exits & EXT & 0 \\
Impact of product exits & $\Delta R$ & 325 \\
\hline
\end{tabular}

scenario. This may be the result of a strategy to respond to specific market feedback regarding offering demands. Unfortunately, the changes for this firm had a very negative impact on the mix of products sold even though the total quantity sold remained unchanged. Name this Firm Flub Forward.

In period one, the price on products $\mathrm{A}$ and $\mathrm{B}$ was 12 and the variable costs on products A and B were both 3 . In period two, Firm Flub Forward selectively raised the price on product A to 16, while lowering the price on product $\mathrm{B}$ to 8 , an equal but opposite price change between the two products. Concurrently, the variable costs of product A rose to 5 to accommodate product improvement while that on product $B$ decreased to 1 , an equal but opposite variable cost change between the two products. In period one, the total quantity sold across two products is 75 units with 50 units of $A$ and 25 units of B. In period two, after the strategy was implemented and executed, the total quantity sold was measured to have been unchanged and remained at 75 units; however, the mix had changed to 25 units of $\mathrm{A}$ and 50 units of $\mathrm{B}$. As a result of the unexpected change in mix, profits fell 50 from 675 to 625 due to a failure in managing the mix of offerings
Table 8 Hypothetical two-product firm flub forward

\begin{tabular}{lllllr}
\hline Product & Period 1 & & & Period 2 & \\
\cline { 2 - 3 } \cline { 5 - 6 } & A & B & & A & B \\
\hline Quantity sold & 50 & 25 & & 25 & 50 \\
Price & 12 & 12 & & 16 & 8 \\
Variable cost & 3 & 3 & 5 & 1 \\
Total profit & $\mathrm{R} 1=675$ & & & R2 $=625$ & \\
\hline
\end{tabular}

sold and all impacts from changes in prices and variable costs are countered by the impact of changes in the mix of offerings sold. If there had been no change in the mix, the strategy would have enhanced profits by 50 and the measurements would have revealed the profit impact of changes in prices and variable costs. With the change in mix, the impact of price increases are countered by an equal and opposite impact of price decreases, and similarly for variable costs.

For Firm Flub Forward described in Table 8, the Profit Bridge with Proper Attribution would appropriately yield measurements that show the strategy failed due to a change in the mix. See Table 9 and Figure 4.

In Table 10, we provide the business variables across the two periods which ran the strategy and achieved the outcomes of Flub Forward in reverse. Name this Firm Flub Reverse.

In period one, the price on products $\mathrm{A}$ and $\mathrm{B}$ was 16 and 8 , respectively, and the variable costs on products A and B were 5 and 1, respectively. In period two, Firm Flub Reverse lowered the price on product $\mathrm{A}$ to 12 while raising the price on product $\mathrm{B}$ to 12 , an equal but opposite price change between the two products which now brings them to parity. Concurrently, the variable costs of product A decreased to 3, while that on product
Fig. 3 Profit Bridge with proper attributions for firm mix

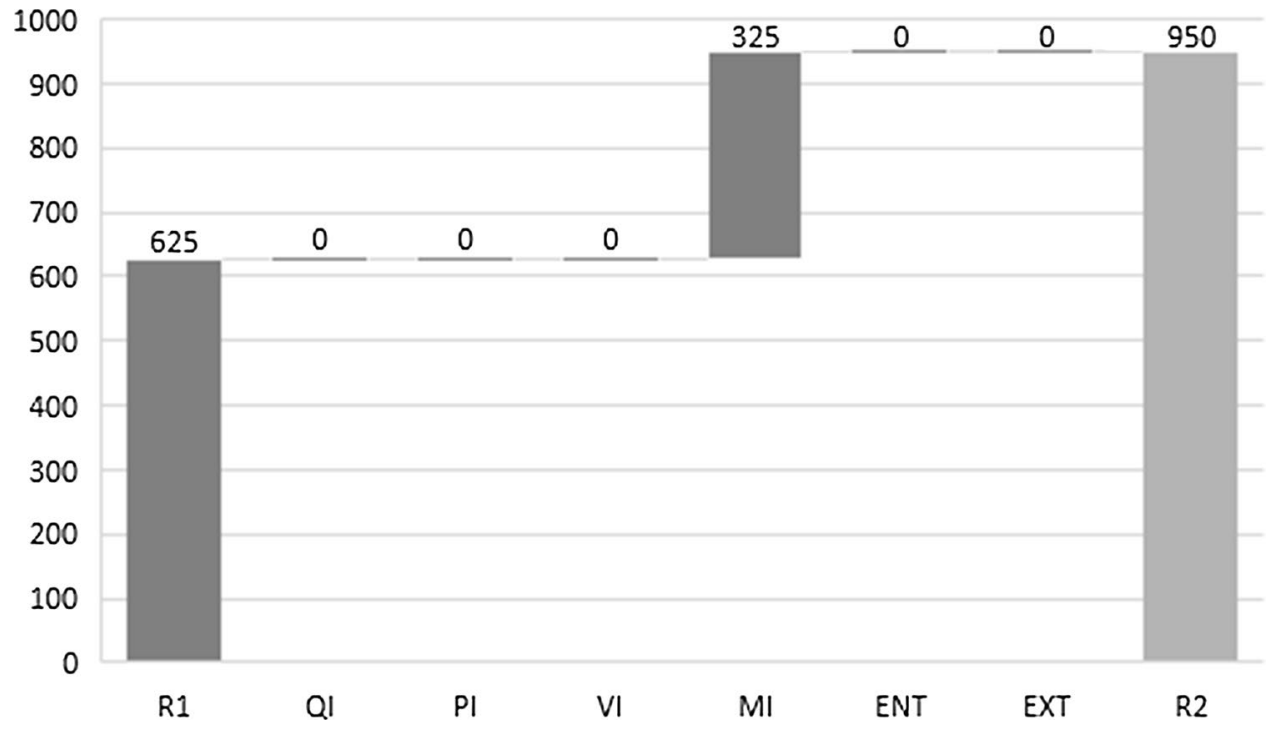


Table 9 Profit Bridge with proper attributions for firm flub forward

\begin{tabular}{llr}
\hline Measurement & Term & Value \\
\hline Impact of changes in quantity sold & QI & 0 \\
Impact of changes in prices & PI & 0 \\
Impact of changes in variable costs & VI & 0 \\
Impact of changes in product mix & MI & -50 \\
Impact of product entrances & ENT & 0 \\
Impact of product exits & EXT & 0 \\
Impact of product exits & $\Delta R$ & -50 \\
\hline
\end{tabular}

B increased to 3, an equal but opposite variable cost change between the two products which now brings them to parity. In period one, the total quantity sold across two products is 75 units with 25 units of A and 50 units of B. In period two, after the strategy was implemented and executed, the total quantity sold was measured to have been unchanged and remained at 75 units; however, the mix had changed to 50 units of A and 25 units of B. As a result, profits rose 50 from 625 to 675 .

The scenario for Firm Flub Reverse is equivalent to running the scenario for Firm Flub Forward in reverse. As such, the measurements of the impacts of various marketing variables should be equal and opposite between the two cases. Usefully, for Firm Flub Reverse described in Table 10, the Profit Bridge with Proper Attribution does appropriately yield measurements that are equal and opposite to those of Firm Flub Forward. See Table 11 and Figure 5.

\section{Profit Bridge with unattributed impacts}

An alternative profit bridge derived by taking a straightforward approach to defining differences in quantities sold, prices, and variable costs would leave some impacts of
Table 10 Hypothetical two-product firm flub reverse

\begin{tabular}{lcrllr}
\hline Product & Period 1 & & & Period 2 & \\
\cline { 2 - 3 } \cline { 6 - 6 } & $\mathrm{A}$ & $\mathrm{B}$ & & $\mathrm{A}$ & $\mathrm{B}$ \\
\hline Quantity sold & 25 & 50 & & 50 & 25 \\
Price & 16 & 8 & 12 & 12 \\
Variable cost & 5 & 1 & 3 & 3 \\
Total profit & $\mathrm{R} 1=625$ & & & $\mathrm{R} 2=675$ & \\
\hline
\end{tabular}

Table 11 Profit Bridge with proper attributions for firm flub reverse

\begin{tabular}{llc}
\hline Measurement & Term & Value \\
\hline Impact of changes in quantity sold & QI & 0 \\
Impact of changes in prices & PI & 0 \\
Impact of changes in variable costs & VI & 0 \\
Impact of changes in product mix & MI & 50 \\
Impact of product entrances & ENT & 0 \\
Impact of product exits & EXT & 0 \\
Impact of product exits & $\Delta R$ & 50 \\
\hline
\end{tabular}

changes unresolved. This directly leads to two failures. One, the choice of period used as a reference impacts the measurements. Two, an unresolved cross term has an uncertain interpretation. These two failures collectively lead to inaccurate and confusing measurements where measurements are made, and uncertainty in the meaning of all measurements made.

This approach, depicted in Figure 12b of United States Patent US 8,4212,598 B2 (Early 2013), is similarly called into question by its authors though they attempt to provide some questionable guidance on resolving its uncertainties.
Fig. 4 Profit Bridge with proper attributions for firm flub forward

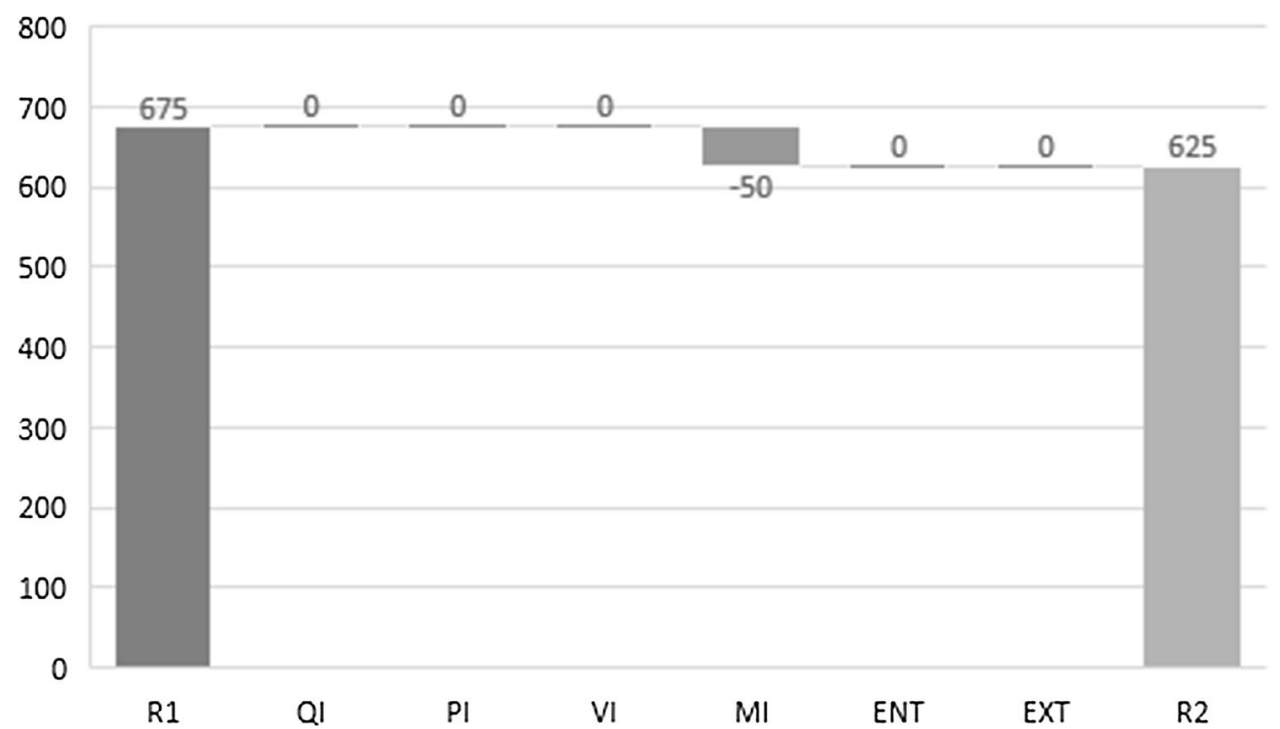


Fig. 5 Profit Bridge with proper attributions for firm flub reverse

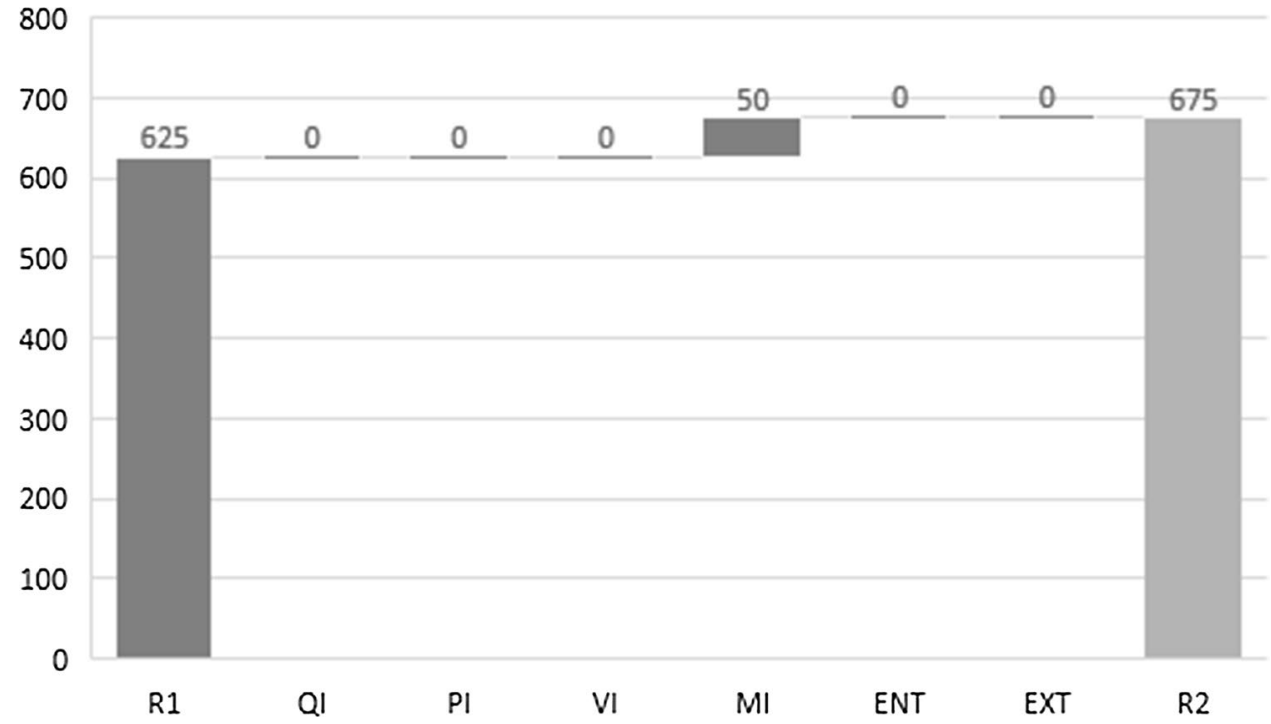

The Profit Bridge with Unattributed Impacts contains an unresolved cross term we will denote at CL. We will demark this profit bridge with the letter L. See Eq. 26.

$$
\Delta R=\mathrm{QL}+\mathrm{PL}+\mathrm{VL}+\mathrm{CL}+\mathrm{ENT}+\mathrm{EXT}
$$

The definitions of the last two terms, ENT and EXT, remain the same and can be found in Eqs. 24 and 25. QL, PL, VL, and CL are defined below.

\section{Definitions}

QL is associated with the impact changes in quantity sold has on profits. It is the sum of the changes in quantity sold times the first period's prices. Using Eq. 10, QL can be written as

$\mathrm{QL}=\sum_{j \in \mathrm{CONT}} \Delta Q_{j}\left(P_{j 1}-V_{j 1}\right)$

PL is associated with the impact changes in specific variable costs have on profits. It is the sum of the changes in prices times the first period's quantity sold. Using Eq. 11, PL can be written as

$\mathrm{PL}=\sum_{j \in \mathrm{CONT}} Q_{j 1} \Delta P_{j}$

VL is associated with the impact changes in specific variable costs have on profits. It is the negative of the sum of the changes in variable costs times the first period's quantity sold. Using Eq. 12, VL can be written as

$\mathrm{VL}=-\sum_{j \epsilon \mathrm{CONT}} Q_{j 1} \Delta V_{j}$
$\mathrm{CL}$ is a cross term that contains multiple unattributed changes. Using Eqs. 10-12, CL can be written as

$$
\mathrm{CL}=\sum_{j \in \mathrm{CONT}} \Delta Q_{j}\left(\Delta P_{j}-\Delta V_{j}\right)
$$

While algebraically correct, the Profit Bridge with Unattributed Impacts yields poor measurements. Specifically, it leaves a cross term unresolved and having no clear meaning. We can approximate the attribution of this term to other terms in multiple manners, but this overly simplistic approach does not deliver the clarity and accuracy one would require for decision-making.

Thus, this Profit Bridge with Unattributed Impacts suffers from two major shortcomings. (1) We had to choose a single period as the basis of analysis. In the above equations we chose period 1, but we could have chosen period 2 and observed different measurements. This results in an asymmetry in measurements between going forward in time and backwards in time and could lead to confusion. Such a result is clearly inelegant as the profit bridge should not be contingent on an arbitrary choice in frame of reference nor exhibit an asymmetry in the direction of time's arrow. (2) The final equation has a leftover cross term to which no clear interpretation of its meaning can be made. That is, we cannot separate the impacts due to changes in quantity sold, price, variable costs, nor mix in its interpretation.

\section{Application}

While it should be obvious that the cross term leads to uncertainty in the meaning of its measurements, it may be less obvious that the construction of this profit bridge can lead to 
Table 12 Profit Bridge with unattributed impacts for firm flub reverse

\begin{tabular}{llr}
\hline Measurement & Term & Value \\
\hline Impact associated with changes in quantity sold & $\mathrm{QL}$ & 100 \\
Impact associated with changes in prices & $\mathrm{PL}$ & 100 \\
Impact associated with changes in variable costs & $\mathrm{VL}$ & -50 \\
Impact associated with changes in product mix & $\mathrm{CL}$ & -100 \\
Impact of product entrances & $\mathrm{ENT}$ & 0 \\
Impact of product exits & $\mathrm{EXT}$ & 0 \\
Impact of product exits & $\Delta R$ & 50 \\
\hline
\end{tabular}

inaccurate and confusing measurements where measurements are made.

To clearly and simply demonstrate the failure of this approach, we will apply the Profit Bridge with Unattributed Impacts on our hypothetical two-product Firm Flub Reverse described in Table 10. We leave it to the reader to apply it to other scenarios and discover its flaws. The Profit Bridge with Unattributed Impacts would yield the following measurements found in Table 12 and Fig. 6.

These measurements would confusingly indicate a change in quantity sold is improving profits by 100 despite there being no change in the total quantity sold. Moreover, they would indicate a loss of profits due to an unattributed cross term of 100 , which has no clear allocation to a specific marketing variable under management or outcome being observed. Hence, this is a poor profit bridge as it leads to misleading, inaccurate, and confusing measurements.

\section{Profit bridge subsuming mix changes in the quantity sold term}

It is possible to cleanly attribute changes in profits to changes in quantity sold, prices, or variable costs by considering averages of individual business variables across the time periods as the point of reference rather than taking a single period as the point of reference. This addresses both of the challenges of (1) being independent of the choice of period for the basis of the analysis and (2) having no cross term which has no clear interpretation. Outside of a single product firm, a straightforward application of using averages across time periods can lead to confusing and inaccurate measurement of the impact of changes in quantity sold by failing to consider changes in mix from changes in quantity sold.

The Profit Bridge with Subsuming Mix Changes in the Quantity Sold Term will be demarked with the letter M. See Eq. 31.

$\Delta R=\mathrm{QM}+\mathrm{PM}+\mathrm{VM}+\mathrm{ENT}+\mathrm{EXT}$

The definitions of the last two terms, ENT and EXT, remain the same and can be found in Eqs. 24 and 25. QM, $\mathrm{PM}$, and VM are defined below.

\section{Definitions}

QM is associated with the impact of changes in quantity sold on profits. It is the sum across all continuing products of the changes in quantity sold times the difference in the
Fig. 6 Profit Bridge with unattributed impacts for firm Flub Reverse

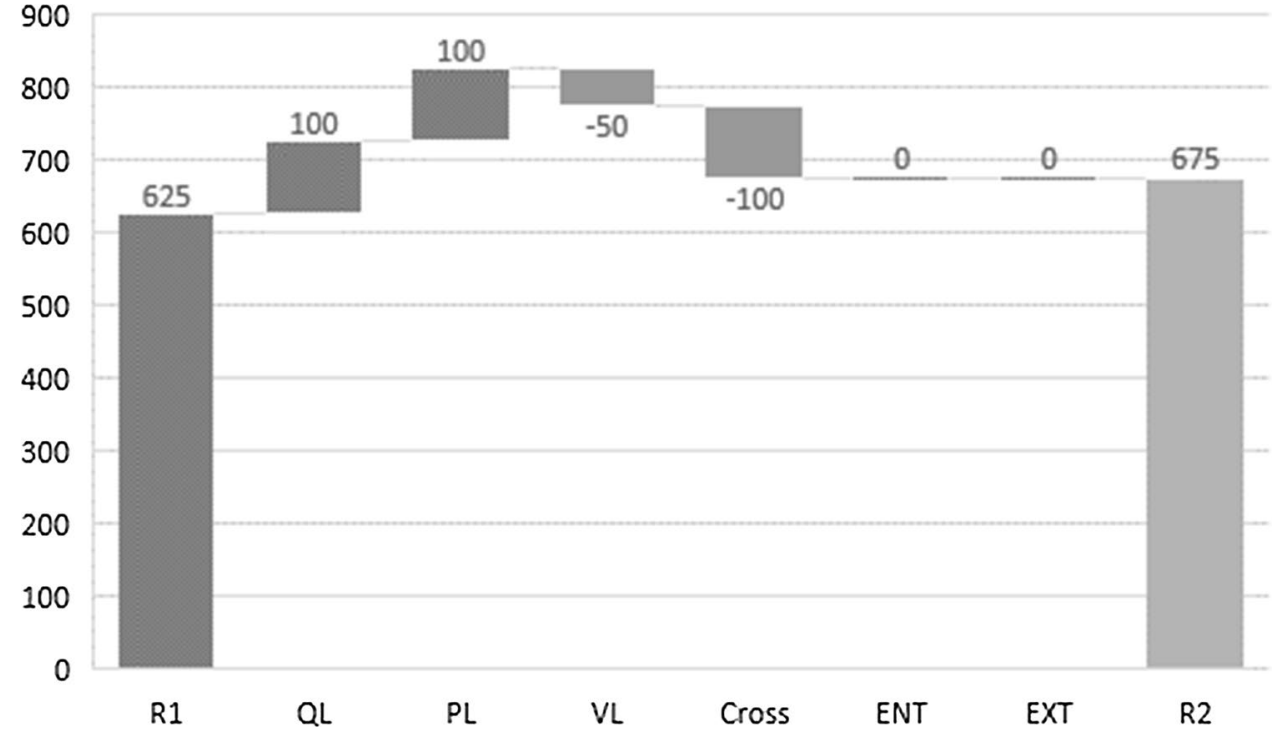


Table 13 Profit Bridge subsuming mix changes in the quantity sold term for firm mix

\begin{tabular}{llr}
\hline Measurement & Term & Value \\
\hline Impact associated with changes in quantity sold & QM & 325 \\
Impact associated with changes in prices & PM & 0 \\
Impact associated with changes in variable costs & VM & 0 \\
Impact of product entrances & ENT & 0 \\
Impact of product exits & EXT & 0 \\
Impact of product exits & $\Delta R$ & 325 \\
\hline
\end{tabular}

average price and variable cost across the two periods. Using Eqs. 7-8 and 10, QM can be written as

$\mathrm{QM}=\sum_{j \in \mathrm{CONT}} \Delta Q_{j}\left(\bar{P}_{j}-\bar{V}_{j}\right)$

PM is associated with the impact of changes in specific prices on profits. It is the sum across products of the changes in prices times the average quantity sold across the two periods. Using Eqs. 6 and 11, PM can be written as

$\mathrm{PM}=\sum_{j \in \mathrm{CONT}} \overline{Q_{j}} \Delta P_{j}$

VM is associated with the impact changes in specific variable costs have on profits. It is the sum across products of the changes in variable costs times the average quantity sold across the two periods. Using Eqs. 6 and 12, VM can be written as

$\mathrm{VM}=-\sum_{j \in \mathrm{CONT}} \overline{Q_{j}} \Delta V_{j}$

These definitions lead to an algebraically correct profit bridge and are definitively more elegant than those used in the Profit Bridge with Unattributed Impacts. For a single product firm, this approach will suffice. However, it fails to properly attribute all changes in business variables to their profit impact when considering a multiproduct firm. This will lead to confusing and inaccurate measurements.

\section{Application}

While this profit bridge will perform well for Firms Growth and Price, it provides unclear measurements for Firms Mix, Flub Forward, and Flub Reverse. Let us demonstrate the failure of this approach on our hypothetical two-product Firm Mix described in Table 6. The Profit Bridge Subsuming Mix Changes in the Quantity Sold Term would make the following measurements found in Table 13 and Figure 7.

While the price and variable cost terms are zero because there were no changes in prices or variable costs, the quantity term is non-zero. This belies the clear observation that the total quantity sold has not changed in our hypothetical Firm Mix, rather the mix of products sold has changed. Subsuming the impact of changes in mix within the quantity sold can misleadingly indicate offering sales are up or down when they have not changed and fails to clarify the importance of weighted average prices, variable costs, or the mix itself. This lack of clarity in the meaning of the measurement can lead to inappropriate managerial and investment decision-making. In this case, it looks like sales quantities have increased despite the fact that there were no overall changes in quantity sold. Instead, decision makers should have measurements that clearly indicate how different marketing variables are performing. Hence, this too is a poor profit bridge for enabling decision-making.
Fig. 7 Profit Bridge subsuming mix changes in the quantity sold term for firm mix

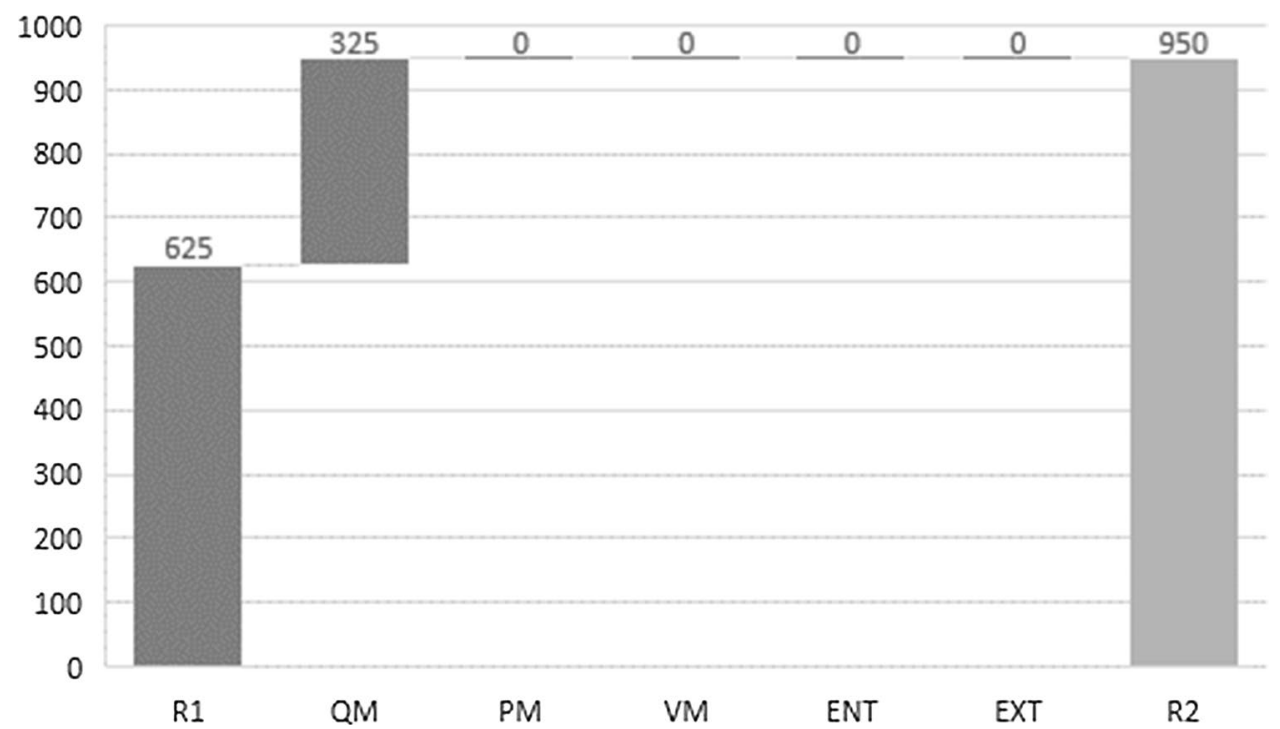




\section{Profit Bridge subsuming mix changes in the price and variable cost terms}

We can improve the measurement of the impact of changes in quantity sold by using the quantity weighted averages and differences of prices and variable costs of specific periods. This will address the challenge of inappropriately attributing a change in the mix of products sold to a quantity sold term, but it will bury the attribution of the change in mix within the change in prices and variable costs even when those prices and variable costs did not change.

For shareholder communication, this approach appears to be sufficient as it is what executives appear to be communicating to their boards and shareholders. For managerial decision-making, however, it fails to disentangle the impacts of changes in prices and variable costs from those of changes in mix. This is important when specific strategies are undertaken to separately improve prices without changing the mix or change the mix without changing prices or variable costs. And there are many strategies that aim to address a single marketing variable, be it price, variable costs, or mix, without impacting any other in an aim to improve profits.

The Profit Bridge with Subsuming Mix Changes in the Price and Variable Cost Terms will be demarked with the letter N. See Eq. 35.

$\Delta R=\mathrm{QN}+\mathrm{PN}+\mathrm{VN}+\mathrm{ENT}+\mathrm{EXT}$

The definitions of the last two terms, ENT and EXT, remain the same and can be found in Eqs. 24 and 25. QN, $\mathrm{PN}$, and VN are defined below.

\section{Definitions}

The quantity weighted average prices and variable costs of a specific period are found by including their mix contribution in that period. These definitions align with the common definition of a period's average price and variable costs. The quantity weighted average price in period 1 and 2 using Eqs. 4-5 are

$$
\overline{P_{1}}=\sum_{j \in \mathrm{CONT}} M_{j 1} P_{j 1}
$$

$$
\overline{P_{2}}=\sum_{j \in \mathrm{CONT}} M_{j 2} P_{j 2}
$$

and the quantity weighted variable cost in period 1 and 2 are

$$
\overline{V_{1}}=\sum_{j \in \mathrm{CONT}} M_{j 1} V_{j 1}
$$

$\overline{V_{2}}=\sum_{j \epsilon \mathrm{CONT}} M_{j 2} V_{j 2}$

This time, define averages and difference in price and variable cost using quantity weighted average prices and variable costs for given periods. Thus, the quantity weighted average price and variable cost across periods becomes

$\bar{P}=\left(\overline{P_{2}}+\overline{P_{1}}\right) / 2$

$\bar{V}=\left(\overline{V_{2}}+\overline{V_{1}}\right) / 2$

and the change in quantity weighted average price and variable cost between periods becomes

$\Delta \bar{P}=\overline{P_{2}}-\overline{P_{1}}$

$\Delta \bar{V}=\overline{V_{2}}-\overline{V_{1}}$

QN is associated with the impact of changes in quantity sold on profits. It is the product of the change in quantity sold times the difference in quantity weighted average price and variable cost across the two periods. Using Eqs. 40-41 and 17, QN can be written as

$\mathrm{QN}=\Delta Q(\bar{P}-\bar{V})$

$\mathrm{PN}$ is associated with the impact of changes in prices on profits. It is the product of the change in quantity sold times the change in quantity weighted average price across the two periods. Using Eqs. 14 and 42, PN can be written as

$\mathrm{PN}=\bar{Q} \Delta \bar{P}$

$\mathrm{VN}$ is associated with the impact of changes in variable cost on profits. It is the product of the change in quantity sold times the change in quantity weighted average variable cost across the two periods. Using Eqs. 14 and 43, $\mathrm{VN}$ can be written as

Table 14 Profit Bridge subsuming mix changes in the price and variable cost terms for firm mix

\begin{tabular}{llr}
\hline Measurement & Term & Value \\
\hline Impact associated with changes in quantity sold & QM & 0 \\
Impact associated with changes in prices & PM & 250 \\
Impact associated with changes in variable costs & VM & 75 \\
Impact of product entrances & ENT & 0 \\
Impact of product exits & EXT & 0 \\
Impact of product exits & $\Delta R$ & 325 \\
\hline
\end{tabular}


Fig. 8 Profit Bridge subsuming mix changes in the price and variable cost terms for firm mix

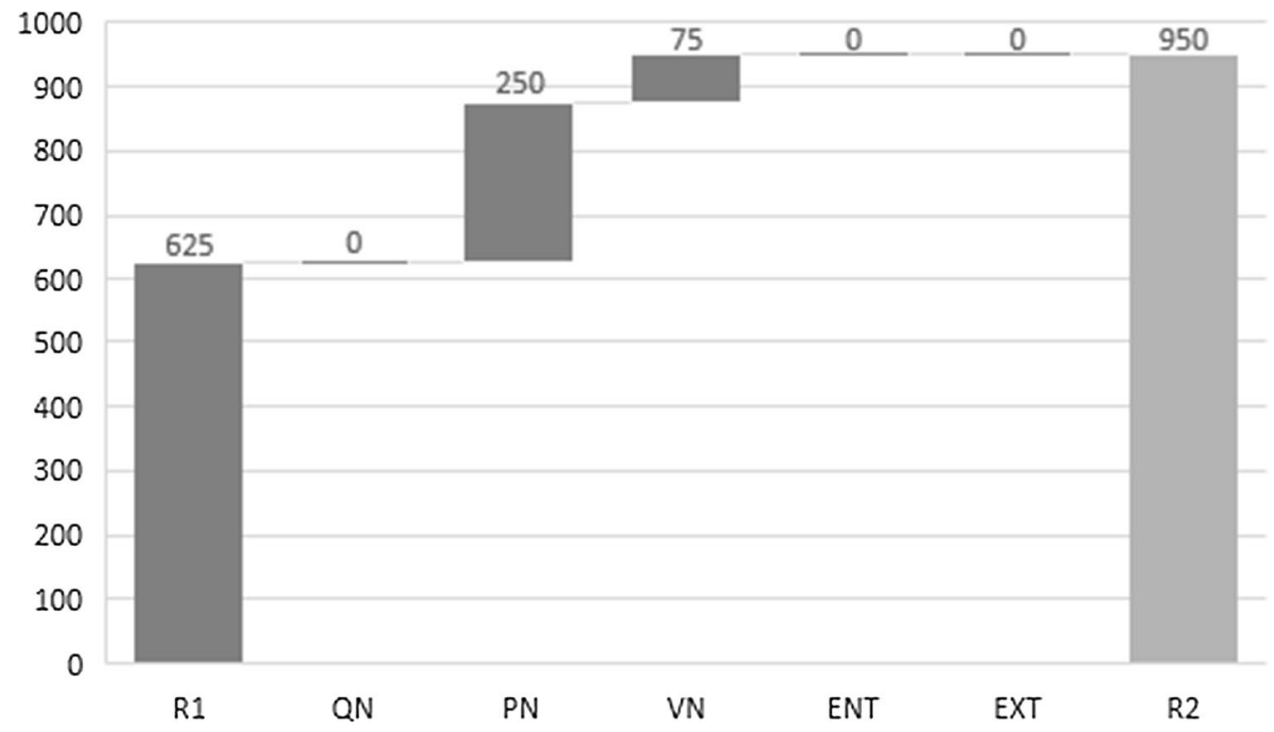

$\mathrm{VN}=-\bar{Q} \Delta \bar{V}$

\section{Inelegant Profit Bridge with misattribution}

These definitions lead to an algebraically correct profit bridge. Unfortunately, no term explicitly demonstrates the impact of the changes in product mix sold. Instead, this impact is subsumed within the overall change in prices and variable costs. This too can lead to confusing and inaccurate measurements when prices and variable costs have not changed, but the mix of products has.

\section{Application}

While this profit bridge will perform well for Firms Growth and Price, it does not fully resolve the impact of changes in mix for Firms Mix, Flub Forward, and Flub Reverse. Let us demonstrate the shortcomings of this approach on our hypothetical two-product Firm Mix described in Table 6. The Profit Bridge Subsuming Mix Changes in the Price and Variable Cost Terms would make the following measurements found in Table 14 and Figure 8.

With this profit bridge, the quantity sold attribution term is appropriately zero because the total quantity sold remains the same across both periods for our hypothetical Firm Mix. It accurately indicates that changes in weighted average prices and variable costs impacted profits. However, Firm Mix had no changes in prices and variable costs of specific products. Firm Mix had a change in mix. This approach fails to distinguish these effects, a distinction which might be very important in evaluating a strategy that aimed to shift the product mix while leaving prices unchanged, as in the scenario for Firm Mix.
There is a yet a fifth failed profit bridge which merits attention. Like the Profit Bridge with Proper Attribution, it explicitly identifies the impact of changes in mix on the profit bridge. Unlike the Profit Bridge with Proper Attriperiod of time as a reference, leading to a solution which lacks symmetry (inelegance), and therefore, it will demonstrate asymmetry between looking forward and backward in time and misattributes impacts across multiple business variables. This misattribution of impacts leads to inaccurate measurements. ${ }^{1}$

A similar set of equations can be found in United States Patent 8,412,598 B2 (Early 2013). Specifically, it is similar to Eqs. 1, 2, 3, 4, and 6 of Patent 8,412,598 B2 with simplifying assumptions of no exchange rate changes and a conversion to examining profit changes instead of simply revenue changes.

One can presume that these are the equations used by the software vendor which sponsored the patent as well other software vendors in the pricing industry since mathematical equations are not patent protected. As such, many software vendors may currently be misrepresenting the profit bridge today and making inaccurate measurements.

The Inelegant Profit Bridge will be demarked with the letter S. See Eq. 47.

\footnotetext{
1 The impetus of this study was the inelegance of solution provided in the patent, which led to the creation of the alternative solutions and the identification of the failures of this inelegant solution and possible alternative constructions.
} bution, the Inelegant Profit Bridge uses one or the other 
$\Delta R=\mathrm{QS}+\mathrm{PS}+\mathrm{VS}+\mathrm{MS}+\mathrm{EXT}+\mathrm{ENT}$

The definitions of the last two terms, ENT and EXT, remains the same and can be found in Eqs. 24 and 25. QS, PS, VS, and MS are defined below.

\section{Definitions}

QS is associated with the impact of changes in quantity sold on profits and is defined using the profits of the first period as the point of reference.

$\mathrm{QS}=\sum_{j \in \mathrm{CONT}} \Delta Q_{j} \sum_{j \in \mathrm{CONT}} M_{j 1}\left(P_{j 1}-V_{j 1}\right)$

PS is associated with the impact of changes in prices on profits and is defined using the quantity sold in the second period as the point of reference.

$\mathrm{PS}=\sum_{j \epsilon C O N T} Q_{j 2}\left(P_{j 2}-P_{j 1}\right)$

VS is associated with the impact of changes in variable costs on profits and is defined using the quantity sold in the second period as the point of reference.

$\mathrm{VS}=-\sum_{j \epsilon C O N T} Q_{j 2}\left(V_{j 2}-V_{j 1}\right)$

MS is associated with the impact of changes in product mix sold on profits. MS is inelegantly defined using the second period's unit sales and the first period's prices and variable costs.

$\mathrm{MS}=\sum_{j \in C O N T} Q_{j 2} \sum_{j \in C O N T}\left(P_{j 1}-V_{j 1}\right)\left(M_{j 2}-M_{j 1}\right)$

Unfortunately, these definitions make improper attributions. By inelegantly mixing points of reference between the first and second period, the resulting profit bridge misrepresents the impact of changes in various business variables.

\section{Application}

While this profit bridge will perform well for Firms Growth, Price, and Mix, it does not fully resolve the impacts for Firms Flub Forward and Flub Reverse. Let us demonstrate the failure of this approach on our hypothetical two-product Firms Flub Forward and Flub Reverse described in Tables 8 and 10.
Table 15 Inelegant Profit Bridge for firm flub forward

\begin{tabular}{llr}
\hline Measurement & Term & Value \\
\hline Impact associated with changes in quantity sold & QS & 0 \\
Impact associated with changes in prices & PS & -100 \\
Impact associated with changes in variable costs & VS & 50 \\
Impact of changes in product mix & MS & 0 \\
Impact of product entrances & ENT & 0 \\
Impact of product exits & EXT & 0 \\
Impact of product exits & $\Delta R$ & -50 \\
\hline
\end{tabular}

The Inelegant Profit Bridge for Firm Flub Forward would make the following measurements found in Table 15 and Figure 9.

The challenge here is that Firm Flub Forward clearly had a change in the mix, but the Inelegant Profit Bridge does not detect any impact from the change in mix. This failure arises specifically because it only uses the prices and variable costs in the first period to measure the impact of changes in mix. In any example where the prices or variable costs of different products are the same in period one, the Inelegant Profit Bridge will not identify any impact to the change in mix. For Firm Flub Forward, the impacts of change in mix are measured to be null in the Inelegant Profit Mix, these impacts are then misattributed to changes in price and variable cost. This is not only confusing, but an inaccurate measurement.

The Inelegant Profit Bridge for Firm Flub Reverse should make the same measurements, but of equal and opposite sign. Unfortunately, it does not. Instead, it exhibits an asymmetry in attribution that would make the following measurements found in Table 16 and Figure 10.

For Firm Flub Reverse, we suddenly see a change in mix impacting profits when going backwards in time, whereas there was no impact from a change in mix when going forward in time. Similarly, the impacts from changes in prices and variable costs have not changed, even though we would expect to see an equal but opposite impact in the measurement. There is a clear lack of symmetry in the measurements resulting from the Inelegant Profit Bridge. This is not only confusing, but an inaccurate measurement. Instead, one should use the Profit Bridge with Proper Attribution.

I have privately applied these profit bridges on a real firm to determine whether the minor changes in definitions between them has a significant impact. While we leave it to the reader to test the approaches on their own for I believe I have made my point clear with the hypothetical scenarios and I do not believe further examples are necessary, I will share that I found 
Fig. 9 Inelegant Profit Bridge for firm flub forward

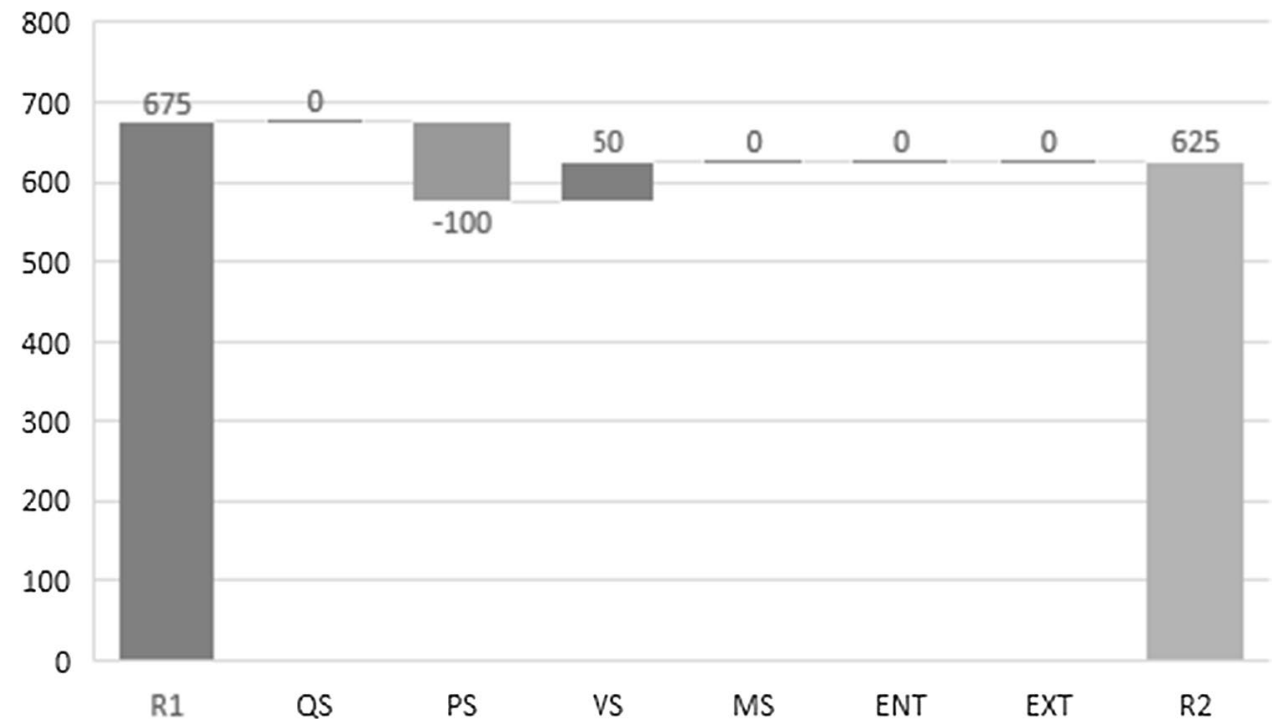

Table 16 Inelegant Profit Bridge for firm flub reverse

\begin{tabular}{llr}
\hline Measurement & Term & Value \\
\hline Impact associated with changes in quantity sold & QS & 0 \\
Impact associated with changes in prices & PS & -100 \\
Impact associated with changes in variable costs & VS & 50 \\
Impact of changes in product mix & MS & 100 \\
Impact of product entrances & ENT & 0 \\
Impact of product exits & EXT & 0 \\
Impact of product exits & $\Delta R$ & 50 \\
\hline
\end{tabular}

significant differences between the Profit Bridge with Proper Attribution and that of the Inelegant Profit Bridge in situ. One could extrapolate from these hypothetical examples that such a finding would be made. The Inelegant Profit Bridge can be simply grossly inaccurate and, therefore, confusing and meaningless.

\section{Discussion}

The superiority of the Profit Bridge with Proper Attribution is a result of its construction. Specifically, it isolates the impact of changes in mix and uses the average across time of different business variables to measure the impact of changes in quantity sold, price, variable cost, and mix. The other four profit bridges suffered from incomplete construction. When striving to provide meaningful, clear, and accurate measurements, details matter.
Fig. 10 Inelegant Profit Bridge for firm flub reverses

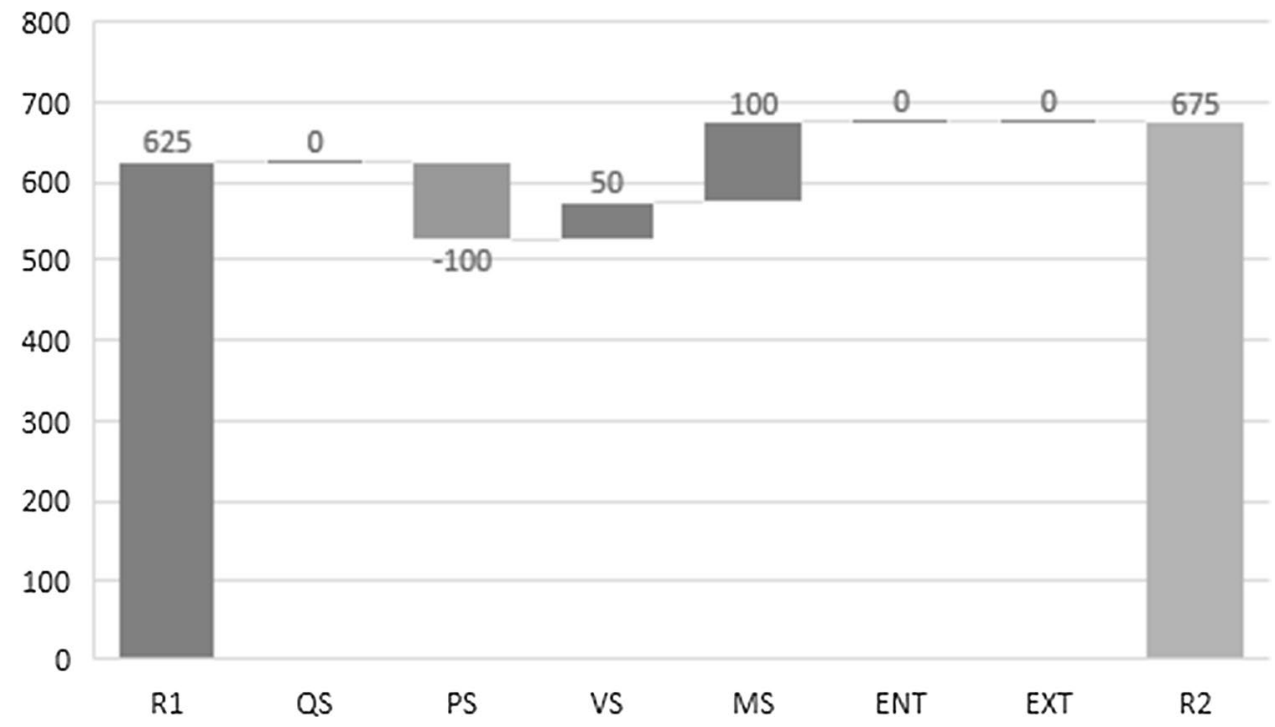


Open Access This article is licensed under a Creative Commons Attribution 4.0 International License, which permits use, sharing, adaptation, distribution and reproduction in any medium or format, as long as you give appropriate credit to the original author(s) and the source, provide a link to the Creative Commons licence, and indicate if changes were made. The images or other third party material in this article are included in the article's Creative Commons licence, unless indicated otherwise in a credit line to the material. If material is not included in the article's Creative Commons licence and your intended use is not permitted by statutory regulation or exceeds the permitted use, you will need to obtain permission directly from the copyright holder. To view a copy of this licence, visit http://creativecommons .org/licenses/by/4.0/.

\section{References}

Early, J., Lai, D. and Johnson, J. 2013. Systems and Methods of a Causality Analyzer. United States Patent 8,412,598 B2.

Gurit. 2014. "Gurit 1HY 2014 Results, Slide 29." SlideShare.net. August 22. https://www.slideshare.net/GuritGroup/gurit-inves tor-presentation-1-hy-2014-final. Accessed 9 Sept 2020.

Lumber Liquidators. 2015."Lumber Liquidators Business Update." SEC.gov. March 12. https://www.sec.gov/Archives/edgar/ data/1396033/000114420415015501/v404301_ex99-1.htm. Accessed 9 Sept 2020.

Matchett, Geraldine. 2016. "2016 Report by the Managing Board." DSM. https://annualreport.dsm.com/ar2016/en_US/6-6-profit-in2016.html. Accessed 9 Sept 2020.

Noranda Aluminium Holding Corp. 2011."Noranda Aluminium Holding Corp First Quarter Conference Call, Slide 5." GetFilings.com. April 20. http://www.getfilings.com/sec-filings/11042
0/Noranda-Aluminum-Holding-CORP_8-K/a6690961ex99_2. htm. Accessed 9 Sept 2020.

Pirelli. 2016. "Ebit Adjussted Bridge, Slide 3 \& 4." Pirelli.com. Accessed September 9, 2020. https://corporate.pirelli.com/corpo rate/en-ww/investors/key-financials/profit-and-loss.

Szramiak, John. 2016. "Here's a look at Harley-Davidson following rumors it might be acquired." Business Insider. July 11 . Accessed September 9, 2020. https://www.businessinsider.com/the-stren gth-of-harley-davidson-amid-acquisition-rumors-2016-7.

Kini Group. n.d. The Margin Bridge - The Power of Understanding Mix. https://thekinigroup.com/margin-bridge-understandingmix/. Accessed 10 Aug 2020.

Vendavo. n.d. Vendavo Margin Bridge Analyzer. https://www.venda vo.com/resources/vendavo-margin-bridge-analyzer-datasheet/. Accessed 10 Aug 2020.

WS Atkins plc. n.d. "WS Atkins plc." SlideShare.net. https://www. slideshare.net/WSAtkins/2015-0611 preliminaryresultspresenta ion. Accessed 10 Sept 2020.

Zurek, Thomas. 2013. "The Hana EDW, Slide 21." Slideshare. SAP. June. https://es.slideshare.net/ukc4/tdwi-hanaedwjun2013. Accessed 9 Sept 2020.

Publisher's Note Springer Nature remains neutral with regard to jurisdictional claims in published maps and institutional affiliations.

Tim J. Smith is a member of the Professional Pricing Society, American Marketing Association, and American Physical Society. He holds a BS in Physics and Chemistry from Southern Methodist University, a BA in Mathematics from Southern Methodist University, a PhD in Physical Chemistry from the University of Chicago, and an MBA with high honors in Strategy and Marketing from Chicago Booth. 